\title{
Chapter 3 \\ Three Reasons for Dealing with Disability, Education and the Majority World
}

\begin{abstract}
This chapter covers aspects of relevance for the topic regarding scientific, disciplinary and methodical relevance, political and developmental relevance (including educational equity) and terminological relevance. This illustrates the importance of the topic regarding the necessity of conducting research on disability, education and the majority world as well as research that includes disability and culture. Thereby, international developments and discussions about disabilityspecific issues (like discussions on inclusive education) are reflected. A final summary of these diverse aspects, which are all meaningful to this work, provides the reader with a first introduction to the topic in a broader framework. Last but not least, the chapter concludes by approaching the field with a question.
\end{abstract}

The topic of interest for this research comprises a multitude of aspects such as disability, education and children; other aspects of relevance are countries of the majority world, ${ }^{1}$ development and poverty, as well as culture, human rights, inclusion, equity and equality. ${ }^{2}$ I give terms like "majority world" or "global South" general preference as they are not loaded with so-called "lag-behind" assumptions like "third world" or "developing countries", which are often discriminating and suggest that "developed countries" are where "developing countries" should develop towards (Fujiura et al. 2005). Several authors refer to this terminology within the field of disability (Barnes and Sheldon 2010; Grech 2011; Turmusani 2004). Yet, the term "developing country" has not been abandoned completely.

Regarding the research as a whole, even more issues can certainly be found when looking more closely at the subject. However, from my perspective, the most relevant aspects for this book are covered. In order to provide you with a clear overview, this chapter is split into three discourses which I consider as relevant: "scientific, disciplinary and methodical", "political and developmental" and "terminological". Naturally, the three aspects are interconnected and overlap; hence, a clear delimitation between these three discourses is not possible.

\footnotetext{
${ }^{1}$ The terms used here interchangeably for so-called developing countries are "majority world" and "countries of the South". So-called developed countries are also referred to as "Western countries", "countries of the North", "minority world", etc.

${ }^{2}$ The order in which these aspects are listed is not meant to be in line with their relevance.
} 


\section{Reason 1: Scientific, Disciplinary and Methodical Relevance}

\section{Research on Disability and the Majority World}

In regard to issues of research in and knowledge about countries of the South, some alarming facts have to be mentioned. "The imbalance between the sheer size of the developing world and what little is known about the lives and life circumstances of persons with disabilities living there should command our attention" (Fujiura et al. 2005, 295). This statement is important in many regards. It is known that the greater part of people with disabilities can be found in the majority world. Around $80 \%$ of the world's people with disabilities live in countries of the South. Furthermore, the life conditions for this group of people are far worse in those countries than in the so-called developed countries (UN Enable 2013; WHO 2011). Regarding the knowledge acquired about the life situations, the challenges and related problems faced by people with disabilities and how these might be solved, much more research has been done in Western countries than in countries of the South. Additionally, it has to be mentioned that Western-led research projects and international funding organisations play an important role in this context. This leads to constructions of disability which are mainly coloured by knowledge based on Western norms and cultures.

A study of projects on inclusive education in the majority world revealed that "in developing countries the implementation of inclusive education is basically undertaken by the NGOs instead of a country's government" (Srivastava et al. 2015, 190).

This distorts global debates about disability in general and issues on how to deal with poverty and disability in particular in countries of the majority world. These facts exemplify the need for research to use Southern knowledge and include people and researchers from countries of the South when looking at people with disabilities and their needs in so-called developing countries. The aspect of education and educational equity deserves special consideration, as it is regarded as one of the most important political issues concerning development (see, e.g. Miles et al. 2012).

Looking at equity in education, clarifying words have to be said regarding the meaning of this concept. According to the OECD policy brief (OECD 2008), two dimensions can be found by looking at equity in education: fairness and inclusion. In more detail, the first aspect refers to circumstances (social as well as personal) that should not interfere with "achieving educational potential" (OECD 2008), whereas inclusion "implies ensuring a basic minimum standard of education for all - for example that everyone should be able to read, write and do simple arithmetic" (OECD 2008). This goal is not compatible with the goals of the capability approach, which are more about having real possibilities to reach goals that can be defined individually than about achieving the same things.

At the same time, both aspects (fairness and inclusion) can't be approached separately: "The two dimensions are closely intertwined: tackling school failure helps to overcome the effects of social deprivation which often causes school failure" (OECD 2008). The OECD does not have so-called developing countries amongst 
their members. However, inclusion and fairness can be taken as aspects which are of similar importance for countries of the global South when moving towards educational equity, as they can (and have to) be defined according to the prevailing culture. Therefore, I want to emphasise the fact that inclusive education is a Western concept which might lead to problems when it comes to its implementation in the global South. Mutua and Swadener state that "a [W]estern definition of inclusion requires that it is implemented in the same way that it is done in the West without taking into account conditions in local communities. Additionally, it illustrates how colonial practices devalued and erased indigenous inclusive practices that did not necessarily mimic [W] estern conceptions of inclusion" (Mutua and Swadener 2011, 213). It is therefore important to approach the concept of inclusion from a different angle. I want to refer to a statement which will appear again later in the book: Inclusion aspires to shape environments in such a way that no one is excluded. Additionally, inclusive education tries to avoid classifications of children with disabilities. Instead it is aimed to switch towards descriptions of the environment in the child's educational surrounding (Biewer 2009a, b). It is of utmost importance to read these sentences with different cultural environments in mind. Feeling like a family may be much more important for people in one culture compared to another. We may not be able to imagine or understand the different values which people with backgrounds different from ours give to certain aspects. But we can try to gain as much knowledge as possible about that culture in order to be able to understand at least a small part of it. By being open to and immerging into other value systems and by leaving out Western approaches and knowledge as far as possible, I am helping to make inclusion meaningful for countries of the South. As an example, it might be interesting to look at the meaning of goals set for an individual person compared to goals set for a community. This also requires questioning the Western concept of inclusion as such. Grech, too, sees the discussing of transferring Western knowledge to the South, especially in relation to development, as an urgent matter:

The inclusion of disability in development is approached as one of incorporation in the existent structure, without considering the implications of this structure for disabled people, notably its colonial and neoliberal foundations and practices. [...]

Overall, the epistemological disengagement from majority world disability not only sustains the little knowledge about disability in the global South (Miles and Ahuja 2007) but also has given rise to a discourse characterised by inferences and generalisations from North to South, where the Western knowledge and practices homogenise, assume and dictate, and where critical issues related to context, culture, economy, history, community and relationships of power among others are often bypassed or reframed to accommodate a minority world view. (Grech 2011, 88)

This underscores the importance of taking a critical stance towards the knowledge which we have gained from our own cultures when dealing with other parts of the world. Aspects like "developing a sense of belonging" and "feeling like a family" can only be seen in the context of the culture where they are observed. Hence, the meaning of those values can only be understood by gaining more knowledge about a society, community and/or culture. We therefore also have to ask ourselves what inclusion and/or inclusive education means in a particular environment and to 
what extent we have to change preconceived convictions. I discuss the issues mentioned by Grech, as well as other aspects, in depth in Chap. 11 on the United Nations Convention on the Rights of Persons with Disabilities (UNCRPD).

In the aforementioned study about projects on inclusive education, it is stated that "there is insufficient empirical evidence on the effects of projects under the aegis of international organisations. It is alarming that governments and other organisations proceed in developing or implementing inclusive education without actual knowledge on possible outcomes" (Srivastava et al. 2015, 190). This is a very critical point. It is especially important to know what inclusive education aims at and how to implement it in a particular environment as well as to be informed about possible consequences. People with disabilities play the main role in proceeding in this way. The need to include people with disabilities in educational efforts must be emphasised especially when referring to development and goals like the Sustainable Development Goals (SDGs). Goal number 4 claims to "ensure inclusive and equitable quality education and promote lifelong learning opportunities for all" (UN 2015). We know that education and development are very strongly interconnected. Different measures have been taken to strengthen and further develop education systems in different countries, amongst them, the gathering of data on the educational situation, in order to decide on further action.

\footnotetext{
By the late twentieth century, quantitative data had gained enormous influence in education systems through the work of the OECD, the European Commission and national system agencies. The creation and flow of data has become a powerful governing tool in education. [...] Comparison between pupils, costs, regions and states has grown ever more important. The visualization of this data, and its range of techniques, has changed over time, especially in its movement from an expert to a public act. Data began to be explained to a widening audience to shape its behaviors and its institutions. (Lawn 2013, abstract)
}

From a quantitative perspective, the quality and scope of available statistics on populations in the majority world have to be viewed critically. Differing results, for example, restrict authentic references to numbers of people with disabilities. This refers to the fact that statistics of different investigations on the same topic frequently reach different results (Fujiura et al. 2005). Numbers are often the most important aspect for governments or organisations to react to certain conditions. Additionally, when regarding disability statistics in particular, they comprise a myriad of challenges. For example, definitions of what is and what is not to be "identified" as a disability and to what extent these definitions confront researchers with problems must not be underestimated (Fujiura et al. 2005, 295). In 2001, the United Nations published a paper on "Guidelines and Principles for the Development of Disability Statistics". ${ }^{3}$ The suggestions address managers of disability programmes as well as researchers. There is a clear recommendation of using the International

\footnotetext{
${ }^{3}$ It is very problematic to try to classify people by referring to disabilities. It strengthens a deficitoriented approach rather than looking at capabilities and the environment that is often responsible for barriers and hence deficits.
} 
Classification of Functioning, Disability and Health (ICF) ${ }^{4}$ (WHO 2001) as a tool for investigation and as an orientation for definitions of disabilities (UN 2001). Different critical references to the ICF already exist, predominantly - but not only concerning terminological issues (see, e.g. Badley 2008; Biewer 2002; Chapireau 2005; Hirschberg 2003; Hollenweger 1998). I am examining the ICF itself in more detail in the chapter on "International Development regarding Access to Education", in the chapter on "Models of Disability" and especially in the chapter on "Facts and Challenges regarding Grounded Theory, the ICF and Ethical Issues". As indicated above, a lack of knowledge and tools for collecting information about disability and the situation of people with disabilities in the majority world leads to disadvantage and invisibility of the topic as such. The search for appropriate tools and methods in research is therefore of utmost importance and must not be restricted to quantitative data.

\section{Methodical Aspects}

The focus of this book is on qualitative methods for gathering data and information about the situation of children with disabilities in Ethiopia. In their report on using qualitative methods in studying the link between disability and poverty, Ingstad and Grut state that " $[t]$ here are several reasons for choosing a qualitative design. A qualitative approach is likely to be chosen when the focus involves an interpretive approach in which the aim is to understand and interpret the meaning the different experiences have to the individuals" (Ingstad and Grut 2005, 6). As this research focuses explicitly on different perspectives on how children experience the aspect of inclusion, exclusion and participation, it seemed most logical to me not to resort to quantitative methods for answering emerging questions.

Another reason why to put emphasis on qualitative research is that qualitative methods allow the researcher to explore people's experiences, their personal perspectives and convictions. In the field of research which this study belongs to, with children with disabilities at its centre, delicate and sensitive issues (especially regarding the children and parents) can come up during the research. This means that the phenomenon under research is difficult to study. In these cases qualitative methods are more useful instruments for research than quantitative instruments (Denzin and Lincoln 2005; Ingstad and Grut 2005). On the other hand, there is the challenge of conducting qualitative research in a foreign culture in a country of the majority world. In their book, which was originally published in 1983, Bulmer and Warwick state:

\footnotetext{
${ }^{4}$ The International Classification of Functioning, Disability and Health (ICF) will be presented in more detail in later chapters. It has to be acknowledged that the ICF and ICF-CY (child and youth version) will appear in different contexts: in political contexts (international classification), terminological contexts (models of disabilities) as well as in the context of being used as a language for starting the investigation at hand (framework).
} 
The conduct of social research in developing countries is an important issue. For Third World countries rely increasingly upon social science methods to gather data which is used by governments both for development planning and in day-to-day administration. The results of social inquiry are not just fed back to fellow academics, but are used to influence the life chances of millions upon millions of people. The means by which social data are collected, and the quality of the data which result, are therefore issues of major importance [...]. (Bulmer and Warwick 1993, 3)

It might be ambitious to expect social research to have an impact on millions of people, but it is certainly realistic for some research. It is a fact that qualitative methods can lead to insights into people's lives that are capable of identifying conditions that are affecting their quality of life. Consequently, this can allow interventions that might improve the respective life situations (and hence affect millions of people).

At this point I have to state that the research at hand is classified as basic research rather than implementing new ideas or interventions and studying how they affect certain situations. It hence has to be understood as research that analyses the situation of children with disabilities as such. This can provide a basis for further research. Consequently, the importance of conducting quality research on social issues has to be emphasised as a major tool for elucidating the situations of people living under problematic conditions. In this context it has to be pointed out that it is not exclusively the "developed" countries who should initiate research and who are going to change the life situations of people and point at directions of development. The research must rather be conducted by the countries in question and their people themselves to identify their own needs. Although the research at hand was initiated by a Western university and Western researchers, I accomplished it in partnership with Addis Ababa University, involving a team of researchers from the Department of Special Needs Education throughout the research process. Additionally, I consulted and involved the expertise of ministries, schools, teacher education institutions as well as NGOs and associations for people with disabilities. In this way, I tried to obtain emic as well as etic perspectives on the topic and to uncover my possible biases.

\section{Research Including Culture and Disability}

As mentioned above, only a small number of qualitative studies on people with disabilities in the majority world are available (McEwan and Butler 2007). Within these, at the beginning especially, studies in the field of anthropology started to engage in the topic (Ingstad and Grut 2005; Ingstad and Whyte 1995, 2007; Neubert and Cloerkes 2001; Kohrman 2005). Regarding cultural diversity and disability, Ingstad and Whyte realised already during their first meeting in 1983 that a big gap existed in the literature on people with disabilities in so-called developing countries. Most of the existing research had been related to Europe and North America (Ingstad and Whyte 1995, 9f). It can be assumed that this situation has changed to a certain extent and more research can be found on the topic (e.g. Barnes and Sheldon 2010; 
Beyene and Abate 2005; Braithwaite and Mont 2008; Campbell 2010; Elwan 1999; Fujiura et al. 2005; Grech 2011; Leonhardt 2002; Mengistu 1994; Peresuh and Ndawi 1998; Tomlinson and Abdi 2003; Zehle 2008 etc., just to mention a few).

What is important to note in this regard is that usually the research studies are initiated and led by Western researchers.

Hatton (2004), however, addresses one aspect regarding existing gaps in research in the context of disability and the majority world. He criticises the unsatisfactory attention which research papers pay to culture, basing themselves on a picture of average cultural norms. This approach can lead to the wrong assumption that those norms are interculturally applicable. Arzubiaga et al. (2008) state that researchers from the fields of psychology and special needs education work mainly in "cultureblind" areas. When looking at systematic analyses of empirical studies that have been published over a longer period, it is striking that researchers have been neglecting the role of culture in human development in journals for psychology, special needs education and school psychology. Furthermore, the authors note that analyses and documentation of data that focus on this aspect are missing. Such data could provide researchers and the public with new findings about achievements and behaviour patterns of students which are not only based on the students' deficits (Arzubiaga et al. 2008, 311). According to Neubert and Cloerkes (2001), this gap in research can be explained by the topic's position in a pocket area. The subject that is delimited by the terms "culture" and "disability" is usually dealt with in the areas of sociology of disability and ethnology. It hence constitutes an interdisciplinary field of research. In both of these areas, however, the subject is not the main interest of research. Connections are more likely to be found in the areas of ethnopsychology and obsession (Neubert and Cloerkes 2001, 6). An interdisciplinary approach towards the topic of the book at hand is therefore regarded as desirable as it could broaden the perspectives on disability including cultural aspects. In fact Neubert and Cloerkes are looking at the situation that can be found in the area of ethnology. Thereby, they are criticising first and foremost the low consideration of disability within the research area. In the third edition of their publication, the authors mention that they still feel reassured regarding their assumptions of a gap within research on disability and culture. Hence, they criticise that research does not involve the subject by conducting further research (Neubert and Cloerkes 2001, 7). However, the book at hand aims at paying special attention to the aspect of culture related to disability in Ethiopia.

Even though a mainstream culture exists, the population in Ethiopia is heterogeneous in social and cultural dimensions through external and internal migration processes. As a result, social inequalities are problems faced by the educational systems in different ways. Generally, it can be stated that cultural diversity as well as cultural transformation processes influence certain developments in an educational system (Luciak and Khan-Svik 2008; Tirussew 2005). Therefore, culture has to be regarded as a variable that on the one hand influences education and on the other hand determines perspectives on disability. "Culture" itself cannot be regarded as static (Holzer et al. 1999, 15) as it changes over time. There are geographical as well as historical differences regarding the meaning of culture. The concept of cul- 
ture is therefore very difficult to identify and to describe (Mason 2007, 175). The concept of Nieke (2008) will be used for the purposes of the book at hand. His concept is a heuristic one that is open for changes. For Nieke, culture is the overall sum of collective patterns of orientation in a lifeworld (Nieke 2008, 50). It has to be assumed that a person is influenced fundamentally by his or her culture and the culture of its predecessors. The idea of "lifeworld" (Lebenswelt) is introduced as an essential term to Nieke's discussion of culture. He states that the lifeworld of a person or group is mainly constituted by the patterns of orientation which are used for orientation in the respective lifeworlds (Nieke 2008, 65). Furthermore, the term lifeworld represents an explanatory approach that is able to describe elementary interpretations within a culture as the only possible and true ones (Nieke 2008, 52).

Hence, the term culture is understood as the availability of patterns of orientation for a person that help her to adjust within a community. The mentioned patterns of orientation are passed on to that person by her environment from the very beginning of her life. In the context of research within an intercultural framework, relevant patterns of orientation have to be identified. These patterns have to be analysed regarding their specific meanings in order to be able to obtain access to the lifeworlds of the participants (Schiemer 2013).

In brief, in the book at hand, culture is seen as a concept that is not static, that is passed on from generation to generation, that influences the people who live in that culture, that changes also through the influence of its people and that provides people with patterns that enable them to orient themselves in their lifeworld.

Finally, the relation between culture and disability is a very important one in the research at hand. On the one hand, I am a foreigner in the culture under investigation, and on the other hand, Ethiopia is a country with a great ethnical diversity. It therefore has to be analysed how disability is perceived and constructed within this culture and which patterns of orientation are offered to the members of the community in order to be able to deal with it.

\section{Reason 2: Political and Developmental Relevance}

The Economic and Social Council of the United Nations "expressed concern about the persistent gap that continued to exist between policy and practice regarding mainstreaming the perspective of persons with disabilities in realizing the Millennium Development Goals" (UN 2009, 3). These words can be found in the report of the secretary general on mainstreaming disability in the development agenda. Millennium Development Goal number two strived for achieving universal primary education(UNDP 2010).

The aforementioned report of the secretary general furthermore highlights that the mentioned policy and practice gap have to be filled by taking "concrete measures to incorporate the perspective of persons with disabilities and accessibility requirements in relation to such issues as poverty eradication, education and training, employment and the allocation of resources" (UN 2009, 3). It becomes clear 
that the topic of disability has started to be taken more seriously during the last years, also regarding development cooperation. In September 2013, for example, the outcome document of the UN General Assembly High-Level Meeting in New York on disability and development was approved..$^{5}$ Even more important in this context is for it to mention the Sustainable Development Goals which follow the Millennium Development Goals and show a clear development towards including disability as an important issue. The UN developed an infographic about disability-inclusive SDGs. In relation to education, it says: "Guaranteeing equal and accessible education by building inclusive learning environments and providing the needed assistance for persons with disabilities" (UN 2015).

\section{International Developments Regarding Access to Education}

The legacy of inequality generated by imperialism and sustained through unequal global progress has left the majority of children and youth with disabilities and their families in the global South living in stark conditions of inequity and deprivation in almost every sphere of their lives, including education and health care. (Singal and Muthukrishna 2014, 294)

With this statement in mind, it is even more important to look with a critical lens at international agreements, documents, etc. which should actually prevent such developments but often seem to fail to do so.

Next to a number of international declarations and conventions, important developments within the scientific landscape of special needs and inclusive education can be observed. Debates on principles as well as on shifts of paradigms have opened new possibilities and perspectives. One significant development can be seen in the establishment of the International Classification of Functioning, Disability and Health (ICF) (WHO 2001), which is also discussed in Chap. 4.

The predecessor of the version published in 2001 had been published in 1980 under the title "International Classification of Impairments, Disabilities and Handicaps" (ICIDH) (WHO 1980). Following a number of critical statements, the old version has been revised and renamed ICIDH2 and ICF, respectively. The new version differs significantly from the original ICIDH.

Two years before the publication of the initial ICIDH, the so-called Warnock Report had been published (Warnock 1978; Wedell 2008). This report became a benchmark for further developments within special needs and inclusive education. The concept of special needs education represents the most important aspect of the report and was introduced as an alternative to the categories of disabilities which were in use at that time. Consequently, a reorientation in focus took place from whether a child was disabled to whether a child had special needs and how those needs could be reacted to (Dyson 2007). In this context the topic of inclusive education comes up quite often (UNESCO 2005).

${ }^{5}$ Further information can be found at http://www.un.org/disabilities/default.asp?id=1590 (accessed September 25, 2013). 
Throughout the mentioned developments, classifications and categorisations have been rejected increasingly also on an international level (Norwich 2007). This process has been called "de-categorisation" and "de-stigmatisation" by different experts (Benkmann 1994; Cloerkes and Markowetz 2003; Stein 2006; Weisser 2003). The ICF is meant to support this process as a framework and to provide a tool for researchers to achieve internationally comparable results.

In general, it can be stated that the use of the ICF and ICF-CY (child and youth version), respectively, for the area of education has certain advantages. The problem of identifying syndromes in educational environments and of clearly defining the scopes of the problems is a serious one. Potential problems are usually complex and influenced by the environment (Hollenweger 2003, 5). The ICF is often expected to be the adequate tool for making those aspects visible. Hollenweger sees further opportunities for special needs education and science in general through the ICF. She mentions common discourses in research, teaching and practice as aspects that can be improved by using the ICF as a basis. Furthermore, she speaks of the standardisation and operationalisation of terminologies and indicators as benefits (Hollenweger 2003, 4). The updated version of the ICF seems to be promising. By revealing alternative possibilities to describe disability, the classification rejects only medical and deficit-oriented models, and the special consideration of environmental factors plays a major role. The special version for children and youth - the ICF-CY - was only published in the year 2007 (WHO), as it was impossible to satisfactorily describe functions, needs and environmental conditions regarding children through the ICF before that. Generally, the concept of the ICF showed deficits in many areas regarding the environment and life situations of children. The ICF-CY was developed to correct these insufficiencies. These are positive developments regarding the classification. It must be stated nevertheless that the research at hand takes a critical stance towards the ICF/ICF-CY.

Active participation in activities that are relevant for education can be considered as essential for school-aged children, their development and future. Possible barriers that hinder participation must be identified and, if possible, be removed. In regard to the discussion on human rights, in which education is viewed as a fundamental right, as well as in the 1960 "Convention against Discrimination in Education" (UNESCO 1960) and the goals of the "Education for All" programme at the World Education Conference 1990 in Jomtien (Thailand) and 2000 in Dakar (Senegal), disability-related efforts concerning education receive special attention. In Dakar, for instance, the set goal was to ensure access to primary education for everyone by 2015 (UNESCO 2000). This is particularly important for people with special needs, as research shows that children and adults with disabilities generally experience restricted access to education (Lindqvist 1999 cited in Peters 2007b, 98). As children who don't have access to primary education often have limited possibilities in their life later on, it is important to offer education without barriers. It is only in this way that equal opportunities can be secured.

The 1994 Salamanca statement framework for action is one of the most important documents in this context (Ainscow 2007a, 147; Peters 2007b). It indicates that regular schools which follow an inclusive approach are the most effective in com- 
bating discriminatory attitudes, building an inclusive society and achieving education for all (UNESCO 1994). In relation to the Salamanca declaration, Peters remarks that inclusive measures for education are first and foremost built on the concept of social equation (Peters 2007b, 99). Furthermore, she criticises that inclusion was perceived as one of the leading principles and a basic philosophy for UNESCO in 2002 but decreased in importance during the year 2004. Hence, the topic of disability was not as present as expected in the "Education for All" observation report in 2004 (Peters 2007b, 98). However, the big goal of "Education for All" does not only contain the principle of inclusion, it even determines it. "The philosophy of inclusive education is based on the right of all individuals to quality education with equal opportunities - one that develops their potential and respects their human dignity" (Peters 2007b, 99). Insofar, inclusion must be a constant principle of the goal of "Education for All".

Furthermore, as a human right, education is eligible to contribute to human dignity. Tekeste Negash $(2006,10)$ argues that the only solution for unworthy life conditions and poverty would be a new definition of human rights. Missing education is often seen as one of the factors that contribute to poverty. If people have to live under degrading life conditions because of poverty, this might also affect their human dignity. Education has been identified as one of the key aspects for solving many of the problems that exist today for minorities and other marginal groups all over the world (Peters 2007b, 105). It therefore has to receive special attention.

At the World Summit for Social Development 1995 in Copenhagen, it was confirmed that poverty is one basic barrier for education (Peters 2007b). Therefore, initiatives for supporting access to education are of special importance in the area of fighting against poverty, particularly in countries of the majority world (Zehle 2008, 56). In this context, the inclusion of people with disabilities plays a major role, since there are also interdependencies between poverty and disability:

There is a close relationship between poverty and disability: malnutrition, mothers weakened by frequent childbirth, inadequate immunisation programmes, accidents in overcrowded homes, all contribute to an incidence of disability among poor people that is higher than among people living in easier circumstances. Furthermore, disability creates and exacerbates poverty by increasing isolation and economic strain, not just for the individual but for the family: there is little doubt that disabled people are among the poorest in poor countries. (Coleridge 1993, 64)

On this background, it becomes apparent that fighting against poverty can also affect the appearance of disability. Education can definitely be viewed as one instrument against poverty. However, there are many documents and international declarations that contain the implementation of the right to education (UN 2006; UNESCO 1994, 2000). Starting with the "General Declaration of Human Rights", resolution 217 A (III) of December 10, 1948 (UN 1948), lots of situations have already improved. However, the overall goals have seldom been reached satisfactorily. 


\section{Education and Development}

One of the greatest problems facing the world today is the growing number of persons who are excluded from meaningful participation in the economic, social, political and cultural life of their communities. Such a society is neither efficient nor safe. (UNESCO 2003b, 3)

To minimise exclusion and to strengthen societies, education is one of the key elements. It is widely acknowledged that education is one of the most important aspects for human beings to follow the developments of modern societies and to be able to participate in society.

This does not mean that education alone can change a whole society. However, it can provide important impulses for discussions and enable people to participate in fundamental political discussions which can be of great importance to the individual. Similarly, the International Commission on Education for the twenty-first century states for UNESCO that education is "no miracle cure or magic formula" for development. It is rather seen as one of the resources that can lead to appropriate human development which could decrease miseries like poverty, exclusion, ignorance, oppression and war in this world (UNESCO International Commission on Education for the twenty-first century 1996). In this context "feeling like a family" and "developing a sense of belonging" clearly show ways to improve the lives of people (with disabilities) living in poverty (in Addis Ababa) by enabling them to receive quality education. The keyword here is "quality education", as in the schools in which "feeling like a family" was an important value, the quality of education was higher compared to schools without this feeling.

Having identified education as a contributing tool for human development and hence for the improvement of the life situations of many people, it has to be regarded as essential to make education accessible for everyone. Through education, information will be accessible, which is of major importance. "Access to information and means of communication are essential for anyone to realise their rights as a citizen. Without ways to gather knowledge, express opinions or voice demands, it is impossible to obtain an education, find a job or participate in civic affairs" (Krishneer 2013, 20). Knowledge about human rights is difficult to access for people who are illiterate and do not have other possibilities to get information about their rights as citizens and human beings. This deprives them of opportunities for claiming their rights, which might have massive impacts on their lives.

Especially in the majority world, people with disabilities experience a high level of exclusion from education. Particularly in sub-Saharan Africa, education is not a reality for every child (Johnson 2008). For children with disabilities, the situation is even worse. "In principle, all children have the same right to education. In practice, children with disabilities are disproportionately denied this right. In consequence, their ability to enjoy the full rights of citizenship and take up valued roles in society [...] is undermined" (UNICEF 2013c, 27).

The reasons for this degree of exclusion can be found on the one hand within general facilities or teaching methods, as they are usually not accessible for children with disabilities (e.g. multi-storey buildings, use of spoken language not sign lan- 
guage, use of written material and no Braille devices, difficulties in understanding complex issues, teachers' knowledge about special needs, etc.). On the other hand, most of these barriers exist due to a lack of awareness and commitment and due to discriminatory attitudes within a society. As a consequence, people with disabilities are often excluded from various possibilities because barriers do not allow them to access buildings, information, discussions, knowledge, societies, etc. ${ }^{6}$

Johnson articulates that beside the fact that major problems can be found in the educational systems of sub-Saharan countries, there are also problems for children who attend primary schools. He states that less than half of the children enrolled complete their primary education. Furthermore, the skills and knowledge they obtain are at a very low level. Lastly, there is a big gap between rural and urban areas concerning the accessibility of education in general and a difference between the wealth of the families of the children and between girls and boys (Johnson 2008, 7). Children with disabilities are not mentioned by the author. Nevertheless, this group of children has to be referred to especially when talking about discrimination regarding the access to education. The Ethiopian Ministry of Education points out this problem in the following statement:

Ordinary schools tend to refuse to enrol children with special educational needs, particularly those with apparent disabilities. The school management and teachers are unaware of the universal right to primary education. Instead of reporting about children with special needs to kebele ${ }^{7}$ education boards and woreda ${ }^{8}$ education officers to search for solutions and support, schools simply send children back home. The need for guidelines and capacity building is evident. (Ethiopian Ministry of Education 2006, 7)

The Ministry brings up very important issues here. The need of awareness, knowledge and guidelines is highlighted. Nevertheless, it is not only the school management and the teachers who must be blamed for refusing to grant access to school for children with disabilities. The parents and the community as such are also responsible. And last but not least, the government has to find further ways to implement the policies and regulations for inclusive education that exist on paper. The

\footnotetext{
${ }^{6}$ According to the report on the state of the world's children regarding children with disabilities, in Ethiopia, gross enrolment in primary schools is $106 \%$ for male and $97 \%$ for female. The net enrolment rate is $85 \%$ male and $80 \%$ female. Net attendance is $\mathrm{m} 64 \%$ and $\mathrm{f} 65 \%$; and survival until the last class of primary school is $\mathrm{m} 47 \%$ and $\mathrm{f} 84 \%$ (UNICEF 2013b, 116).

According to the Ethiopian Ministry of Education, 43,132 children with disabilities (24,825 boys, 18,307 girls) were enrolled in primary schools (levels 1-8) in the year 2011/2012. Distinctions are made between visually, physically, hearing, mentally impaired and others (Ethiopian Ministry of Education 2012, 37). There is no conversion to percentages of the number, so interpretation is difficult.

7 "Popular term used to describe a cooperative urban neighbourhood association. Kebeles were formed after the nationalisation of all urban land and rentable dwellings in July 1975. These cooperatives became the counterpart of the peasant associations developed under the military government's Land Reform Proclamation of March 1975. After their introduction, kebeles became the basic unit of urban government and served as instruments of socio-political control in urban areas" (Library of Congress Glossary Ethiopia).

${ }^{8}$ Kebele and woreda refer to a certain division of parts of the city into neighbourhoods and districts. Kebele is the smaller unit compared to the woreda.
} 
problem that has been identified by the government regarding special as well as inclusive schools and units is: "All of them are under-resourced. In 2006, there are 17 special needs education schools, 11 of them run by non-governmental organizations" (Ethiopian Ministry of Education 2006, 7). In other words, the government states that it does not have enough resources for establishing the basics for offering special education and even less for supporting special needs and inclusive education. The problem is that such conditions affect children for whom it is difficult to access school in the first place: "Children living in poverty are among the least likely to enjoy the benefits of education and health care, for example, but children who live in poverty and have a disability are even less likely to attend their local school or clinic" (UNICEF 2013c, 1).

Research into disability, culture and education has the possibility to reach beyond superficial problems and obstacles and try to identify anchor points where first steps towards change can start to be effective. It therefore has to be regarded as essential for reaching goals like "Education for All".

\section{Reason 3: Terminological Relevance}

The term "disability" cannot be understood as a self-explaining one. In the last decades, there have been many different perspectives and discourses on how to define disability. The same is true for culture amongst others. Therefore, in the following, some insight will be provided into the discussions on the different terms that are of relevance for this book. This illustrates the importance of putting effort into terminological issues within academic research, as it can add to the discussion by revealing important aspects that might have been neglected before.

\section{Disability}

The uncertainty regarding the phenomenon of disability leads to different ways of solving the dilemma. In this research, the first reference was the ICF-CY with a biopsychosocial model of disability that was used as a language for starting the development of research instruments. Leaving this first point of orientation behind, disability has to be defined from a different perspective so as to be of use for the understanding of the further research process.

"[...] [O]ne is not born a disabled person, one is observed to be one" (Michailakis 2003, 209). This quotation provides an excellent basis for the discussion of disability for this research study. This sentence represents the main issue which the book at hand has been concerned with: it is predominantly the social environment and specific circumstances that are involved in the construction and deconstruction, respectively, of disability. Disability is not a fact but is observed as such by the surrounding. Hence, this book concentrates on the social environment and attitudes 
which children with disabilities are exposed to when undergoing education. The tendency to see in persons with disabilities something that is not "normal", something that does not meet expectations, can be observed in different cultures and societies. In observing differences, Weisser (2005) points out that it is necessary to include the fact that differing expectations exist. He defines disability as an experience that results from a conflict between capabilities and expectations. This means that first disability is perceived as an irritation, as something that does not conform with certain expectations, and is later reinforced through repetition $(2005,16)$. In other words, disability becomes manifest through repeated disappointment of the expectations of a counterpart. In this way, persons with disabilities differ from other persons by continuously irritating the observer. What these expectations are and how they are disappointed differ in various cultures depending on cultural codes, concepts and understandings.

The book at hand focuses on children at school that have been observed by their surroundings to have a disability. Regarding education, the children's social environment has different expectations of children with and without disabilities. Consequently, the former are often expected not to be able to learn. This is of great importance, as education for children with disabilities is essential for opening possibilities of educational equity, social and economic participation and hence a more inclusive society. Therefore, in this book, I understand disability as a phenomenon that is mainly constructed by the (social) environment and influenced by cultural and historical aspects.

In 1995, in their book Disability and Culture, the anthropologists Benedicte Ingstad and Susan Reynolds Whyte state that the term "disability" does not exist as an accepted category in all cultures (also see Stoltzfus and Schumm 2011, xiii). Disability can be seen as something that is constructed, for example, by the members of a community.

In this context, I want to mention an important publication which focuses on disability as more than a social category in late-twentieth-century China. It explores how disability "has been emerging and metamorphosing in China as a social, political, and somatic sphere of existence in recent decades" (Kohrman 2005, xi). Kohrman's book thus gives valuable insights into constructions of otherness and related developments in governmental bureaucracies in China.

Different models of disability have been identified to be able to differentiate between different approaches. Nevertheless, not every model is per se explanatory enough for the concepts and pictures of disability that exist in the world. "Obviously, it would be convenient to have a model of disability that is found superior to others, but the multitude of models that have been developed may in fact reflect the multifaceted nature of disability" (Mitra 2006, 236). This statement describes the problem when trying to define disability for an international or intercultural audience. There is no definition that can satisfactorily define disability on a global level. How disability is seen depends on too many different aspects in too many different cultures in this world. Hence, it is obvious that it does not make sense to look for a globally accepted definition of disability. Instead, it is important to get an idea of the 
concept of disability in the area in which research is conducted. This will enable researchers to interpret data on the basis that has been created on-site.

Disabilities of all kinds can be found in cultures all over the world, in all stages of life. In many cultures in the majority world, the image of disability has been influenced by external perspectives. Very often, a medical concept of disability is prevalent. This can be traced back to international organisations that have worked in that area, research projects, but also to political measures taken by the respective countries (Ingstad and Whyte 1995; Neubert and Cloerkes 2001). In this context it is difficult to deduce the original perception of disability. Therefore, it is essential to get a deep understanding of the way disability is perceived and dealt with in a society. In Ethiopia, aspects like physical limitations, learning abilities, independence, family life and inclusion into sociocultural and leisure time activities as well as the person's contribution to society might play a major role (Tirussew 2005, 7). Additionally, a society's knowledge and awareness of disability are of great importance. The state's actions and policies towards an inclusive society do not necessarily reflect so much the general attitudes of a society as the goals pursued by its government. The failure to achieve a more inclusive society is often rooted in sociopolitical and historical developments.

In regard to Ethiopia, Tirussew states: "There have been as many different views and understandings of disability and persons with disabilities in the history of mankind as there are today in Ethiopia" (Tirussew 2005, 92). This indicates that not only different nations have different perspectives on disability but also within a nation there are different views on disability. Not surprisingly, the people's perception of disability in different contexts is hence more related to the respective community, culture and ethnicity than to the simple boarders of a land mass. In this book I attempt to elucidate the way disability has been constructed by the participants of the research study. Furthermore, I will show that perceptions of disabilities are not static but can change during the lifetime of an individual.

\section{Models of Disability}

Disability is a concept that has been discussed and negotiated for a very long time. Throughout this process of discussion, different directions and models have developed.

The 1960s serve as a starting point to enter the discussion about disability, as this was the time when disability began to become a socio-political issue (in the Western world). During the 1970s the establishment of an international disability movement can be observed. Additionally, the social model of disability started to have an impact on academics, politics and law (Samaha 2007). In the 1980s the formation of the Disabled People's International (DPI) and the establishment of the disability studies (Oliver 1990) followed (Waldschmidt 2005). The year 2001 marks the time when through the publication of the ICF, representing the biopsychosocial model, disability became an issue of mainstreaming in development discussions (WHO 
2001). Many more developments and discourses could be mentioned at this point, but this chapter intends to give a brief insight rather than a broad overview of those discussions. At the same time, I want to put emphasis on the fact that Western knowledge plays a major role also in this context. As Singal and Muthukrishna state very clearly: "Undoubtedly, disability is a hugely debated and politicised issue, especially in relation to how it is defined. However, the models which frame these discussions are exclusively anchored in the industrialised, liberalised and individualistic scripting of the North" (Singal and Muthukrishna 2014, 294).

For this exact reason, I consider it as important to look at those models of disability - Western in origin - as this enables us to understand the biases that cloud and influence our view when looking at disability in the global South.

In the literature, the biomedical model, the social (or socio-political) model and the biopsychosocial model are some of the most discussed ones and will therefore be discussed here as examples (Altman 2001; Bickenbach et al. 1999; Burchardt 2004; McEwan and Butler 2007; Samaha 2007; Smart 2009; Waldschmidt 2005). Approaches towards a cultural model, an individual model, a moral model or a religious model of disability (Smart 2009; Waldschmidt 2005), amongst others, can also be found.

Within these approaches, disability has been described from different perspectives including medical, economic, socio-political and administrative points of view (Altman 2001, 98). It can be quite confusing to try to get an orientation within the different approaches, perspectives and schools of definitions and models. The aim of this chapter is, however, to illustrate briefly the importance which the decision on a certain model of disability can have and to exemplify three of the models in order to provide the readers with an idea of existing differences in models of disability from a Western point of view.

The medical model of disability has been very strong and predominant for a long time and is still referred to in many areas. "Definitions that have been developed for clinical circumstances and administrative implementation are those most commonly known among the total population and have had the greatest influence on our understanding of this phenomenon until recent years" (Altman 2001, 98). It is also a model that has been fought against by institutions and organisations that think in a more holistic way, as it reduces a person to its biological functions and does not include environmental and social factors in the definition of disability.

The social model on the other hand considers society as the one main factor in the construction of disability. "A social model of disability relates a person's disadvantage to the combination of personal traits and social setting" (Samaha 2007, 1251). One of the main actors of this approach is Michael Oliver (1990) and the field of disability studies. Samaha further states: "The model has the potential to knock out ill-considered defences of the status quo based on nature and necessity, just as legal realism and other reform advocacy attempted to unsettle assumptions in the past" $(2007,1308)$. However, the author finishes by noting that this model is also incomplete and in need of more reflection and a broader perspective on disability (Samaha 2007, 1308). 
Last but not least, the biopsychosocial model can be found in the International Classification of Functioning, Disability and Health (WHO 2001). The approach chosen in the classification aims to include medical as well as psychological and social perspectives on disability. This can be considered as a rather ambitious attempt, as the ICF also claims international and intercultural applicability (Üstün et al. 2001). I already mentioned the classification several times and will examine it under a critical lens in Chap. 4.

It can be stated that models of disability have always had and still have a major influence on people's perceptions of disability.

[...] [T]he daily lives of people with disabilities, if and how they are educated, if and where they work, and their social and familial life, in large part are determined by models of disability. Perhaps, most important, models of disability exert a powerful influence on the public perception of disability and public's response to people with disabilities. (Smart 2009, 3)

Smart (2009) also mentions that models of disability go as far as having the power to influence and shape the self-identity of people with disabilities. Generally, models of disability define disability; they are not a reality or a fact but human made. None of the models is morally neutral and all of them are time- and culturebound. Furthermore, each model of disability is reductionist or incomplete (Smart 2009). These aspects spell out the critical stance that should be taken when choosing a model of disability for working on the topic of disability - especially in the context of countries of the majority world.

\section{Special Education, Special Needs Education and Inclusive Education}

Within many schools, the predominant approach to teaching and learning is still based on the grouping of pupils into classes. The rigidities this imposes on children and young people, and the problems it creates for teachers, have been widely recognised. (Wedell 2005, 4)

Special education represents a concept of educating people with disabilities by placing them in separate schools or classrooms in order to be able to implement interventions. It is a concept that has been criticised from its beginning but has also been seen as a solution to the right to education for everyone. Special education has increasingly been seen as a practice excluding rather than including children with disabilities in society and providing them with quality education. Hence, marginalisation is still seen as a consequence of special education practices (Florian 2007, 8f.). Referring to Minow (1990), Florian states that "the laws and policies that are created to protect vulnerable groups also serve to marginalize them" (Florian 2007, 10). She calls it a vicious cycle that is created by the approach of special education, where rights should be protected but at the same time stigmatisation is created (Florian 2007). This problem has been referred to as the "dilemma of difference" by several authors (Florian 2007; Minow 1990; Norwich 2008; Terzi 2008, amongst 
others). Furthermore, Florian identifies two main problems regarding special education: the concept of "normal" that is perceived as common and positive on the one hand and the already mentioned dilemma of difference on the other hand. The most promising approach to tackling these problems would be a change in the discourse about difference (Florian 2007, 12).

The term "special education" was changed into "special needs education" by the International Standard Classification of Education in 1997. According to Florian, a distinction between the two terms is essential. The former has been associated with the need of placement in special schools or classes in order to be able to make an intervention and receive provisions. However, the new term addresses educational interventions and support that aim at special educational needs and are not bound to special classrooms and applicable at any location" (Florian 2007). The "central dilemma", as Florian calls it, remains regardless of which term is used. As soon as there is a deviation from the mainstream like an additional need (support, provisions, etc.), the children in question differ from the rest. This is often assumed to indicate a lower quality as a learner, which makes it the central dilemma (Florian 2007, 13).

The idea of special education as a parallel or separate system of education to that which is provided to the majority of children has been challenged by notions of inclusion in which all children are part of one education system. The problem, of course, is that inclusive education is not a denial of individual difference, but an accommodation of it, within the structures and processes that are available to all learners. (Florian 2007, 10)

The concept of inclusive education follows international developments, which abandon one-dimensional, mainly medically influenced and deficit-oriented models of disability (Altman 2001) and take on a social and multidimensional perspective (Hollenweger 2006, 48ff.). Inclusion aspires to shape environments in such a way that no one is excluded. Additionally, inclusive education tries to avoid classifications of children with disabilities. Instead it is aimed to switch towards descriptions of the environment in the child's educational surrounding (Biewer 2009a, b).

However, the insufficient knowledge about successful implementation of inclusive programmes regarding children with disabilities in schools confronts scientists with serious challenges. It is important to be able to identify the degree of inclusion which students with disabilities are enabled to achieve or not. This would lead to possibilities of identifying aspects that might be responsible for successful or unsuccessful inclusion. Judith Hollenweger (2006) puts the emphasis on studying children's activity and participation in order to identify degrees of successful inclusion. Yet she states that we do not have enough information about the processes in school that possibly affect participation and the acquirement of competencies (Hollenweger 2006, 52). This lack of information describes a gap in research that can also be attributed to other countries, including Ethiopia.

When talking about participation, the question of equal opportunities especially regarding people with disabilities moves into the centre of attention. Hence, barriers

\footnotetext{
${ }^{9}$ See Section "International Developments Regarding Access to Education" for more information on special needs education and the Warnock Report (Warnock 1978).
} 
that hinder participation in private, public and everyday life have to be diminished (Hollenweger 2006). One significant aspect when analysing a problematic situation in a given society is the perception of the problem in the respective culture (Hollenweger 2006, Holzer et al. 1999, 12). In other words, it has great influence where people localise the problem. Regarding the topic of disability, the question would be: do people see the problem located within the person with disability, within society, within the environment or within immediate surroundings and the lifeworld of the person or somewhere else? One could also ask which model of disability is the prevailing one. Additionally, it has to be elucidated which other influencing factors (personal situations, economic aspects, etc.) are considered when people with disabilities and problems they are confronted with get attention. This discussion is of special interest for special needs and inclusive education, as it helps determine problems that cause exclusion. The clarification of perceptions of a problem shows at which points initiatives for improvement have to start.

Inclusive education is mentioned as one of the aspired goals of the Ethiopian government. In other words, inclusion is one of the keywords for the Ethiopian government regarding future developments in the area of education. However, there are difficulties concerning the definition of inclusive education. "Whilst recent years have seen an increased interest in the idea of inclusive education, the field remains confused as to what this implies" (Ainscow 2007b, 3). It is clear that an agenda aiming at inclusive education comes about with "economic and political contexts underpinned by cultural values" (Peters 2007a, 128). One important motor for striving towards inclusive education in Ethiopia is the signing and ratification of the "Convention on the Rights of Persons with Disabilities" (UN 2006) by the Ethiopian government in 2010. But even before this, Ethiopia aimed towards making schools accessible for children with disabilities following the principle of inclusive education.

The UNESCO offers a clear statement on the meaning of inclusive education which should be applicable internationally as it is drawn from the Salamanca Framework of Action which was developed by an international consortium:

The fundamental principle of the inclusive school is that all children should learn together, wherever possible, regardless of any difficulties or differences they may have. Inclusive schools must recognize and respond to the diverse needs of their students, accommodating both different styles and rates of learning and ensuring quality education to all through appropriate curricula, organizational arrangements, teaching strategies, resource use and partnerships with their communities. There should be a continuum of support and services to match the continuum of special needs encountered in every school. $(1994,11 \mathrm{f}$.)

The Salamanca Framework has been mentioned to have further consequences pointing towards a positive development regarding inclusive education. Ainscow states that it has been used "to formulate strategies that will support movements towards inclusive schooling" (Ainscow 1997, 3). Another paper that cannot be ignored in this context is the index for inclusion (Booth and Ainscow 2002), which has been cited as the "most detailed explanation available about what an inclusive school looks like [...] ${ }^{10 "}$ (Ainscow 2007b, 4).

${ }^{10}$ Details can be obtained from http://www.csie.org.uk/ 
In the context of Ethiopia, a developmental aspect which is also connected to the Sustainable Development Goals has to be added. In this context, Peters describes inclusive education as a complex issue with overlapping areas (e.g. health, education, social welfare and employment sectors). This might lead to certain problems for the development of appropriate policies (Ainscow 2007a, 117). She furthermore highlights the problematic aspect of identifying special needs by using classification systems that are not the same between and within countries (Peters 2007a), 118). Generally, it can be stated that inclusive education has been identified as "one of the key strategies to address issues of marginalization and exclusion for vulnerable children, notably girls and disabled children" by the Education for All agreement (Peters 2007a,117). Ainscow sees a difference in the perceptions of inclusive education within countries compared to the international level:

In many countries, inclusive education is still thought of as an approach to serving children with disabilities within general education settings. However, internationally, it is increasingly seen more broadly as a reform that supports and welcomes diversity amongst all learners (United Nations Educational, Scientific and Cultural Organization (UNESCO, 2001). (Peters 2007b, 3)

It has been demonstrated that there are definitions of inclusive education that might not coincide with views on inclusive education taken by different countries. Different processes within countries and on a global level might influence the meaning and aims of inclusive education in a constant process. However, the UNESCO sees a high potential in the concept of inclusive education:

Inclusive education encourages policy-makers and managers to look at the barriers within the education system, how they arise and how they can be removed. These barriers usually include:

- inappropriately-designed curricula

- teachers who are not trained to work with children who have a wide range of needs

- inappropriate media for teaching

- inaccessible buildings. (2003a, 2)

These aspects are certainly some of the most prevailing barriers within different education systems that produce obstacles for people with disabilities to access education. Finally, there are also positive developments regarding the improvement of inclusive education. Different assessments of needs and feasibility studies are taken seriously and are used as contributions to the enhancement of inclusive education. Consequently, these steps lead to sustainability (Peters 2007a, 127).

Inclusive education has been presented as a programme for education that should enable every child to access education on the basis of equal opportunities and emphasis on competencies rather than on deficits. This means that children could be taught together by using their diversity as a potential for the whole class. Special needs therefore have to be identified for every child in the class to be able to support the individual child according to his/her needs. 


\section{Summary of Relevant Aspects}

This study is considered to be of high relevance within the field of international special needs and inclusive education with emphasis on a country of the majority world. By conducting research in the area of disability and education, I want to contribute to filling a gap regarding knowledge about people with disabilities in educational systems in the majority world. This will also contribute to gathering information about what further steps must be taken regarding development, especially considering international goals like the Sustainable Development Goals as well as the "Education for All" framework (UNESCO 2000). The book at hand aims at adding new perspectives to the issue of special needs and inclusive education by concentrating on the experiences and topics raised by participants. It focuses on people who are directly involved in the educational process. Furthermore, the book raises awareness and underscores the importance of improving inclusive education in primary schools in Ethiopia. Last but not least, working on the subject of disability in an international context enriches critical perspectives on classifications and categorisations and contributes to a perspective on disability which includes the environment as one of the main players in constructing disability. Thereby, the aspect of culture is given special emphasis. My research thus contributes to an international discussion about disability, special needs and inclusive education, development and culture.

\section{Approaching the Field with a Question}

On the basis of the previous explanations and illustrations, the book at hand examines the issue of inclusion and exclusion, participation and activity of children with disabilities in an educational environment. The formulation of a research question usually determines the methods that can best answer the question. In qualitative research, a research question can be open for change during the investigation. The primary question about a topic or phenomenon may not be the question that is eventually answered (Ingstad and Grut 2005, 6). In this research study, I am especially interested in processes that can be identified in the interviews. I therefore need to follow the main issues raised by the participants. Phenomena that are of importance to the interviewees can be identified and become significant for the whole research. The most appropriate approach for this is grounded theory. Therefore, in this research, I use grounded theory for approaching the area of research. Birks and Mills note that "[i]n grounded theory, it is the research process that generates the question" (Birks and Mills 2011, 20).

The research question I used to start into the field was:

Which environmental factors facilitate or restrict activity and participation of school-aged children with disabilities in the field of education in Addis Ababa, Ethiopia? 
This question addressed an extensive field that had to be narrowed down at later stages of the investigation. Furthermore, the relatively open formulation allowed me to go more into depth during the research following the content provided by the participants. The enquiry had to be refined in the course of the research according to the ongoing process of interviewing, analysing and interpreting. The question which developed in the course of the research process is the synthesis of different questions which arose in the process of working with the data and in the field:

In which ways does the school access of children with disabilities support or hinder children, parents and teachers in dealing with emotional stress situations which are created through negative cultural and societal attitudes towards disability?

This shows that the focus was placed on three phenomena which proved to be the most meaningful to the participants: the fact that the child with a disability was attending school, the teaching profession as such and the negative societal attitudes towards disability.

\section{References}

Ainscow, M. (1997). Towards inclusive schooling. British Journal of Special Education, 24(1), 3-6.

Ainscow, M. (2007a). From special education to effective schools for all: A review for progress so far. In L. Florian (Ed.), The sage handbook of special education (pp. 146-159). London/ Thousand Oaks/New Delhi: Sage.

Ainscow, M. (2007b). Taking an inclusive turn. Journal of Research in Special Educational Needs, 7(1), 3-7.

Altman, B. M. (2001). Disability, definitions, models, classification schemes, and applications. In G. L. Albrecht, K. D. Seelman, \& M. Bury (Eds.), Handbook of disability studies (pp. 97-122). Thousand Oaks/London/New Delhi: Sage.

Arzubiaga, A. E., et al. (2008). Beyond research on cultural minorities: Challenges and implications of research as situated cultural practice. Exceptional Children, 74(3), 309-327.

Badley, E. (2008). Enhancing the conceptual clarity of the activity and participation components of the international classification of functioning, disability and health. Social Science \& Medicine, 66, 2335-2345.

Barnes, C., \& Sheldon, A. (2010). Disability, politics and poverty in a majority world context. Disability \& Society, 25(7), 771-782.

Benkmann, R. (1994). Dekategorisierung und Heterogenität - aktuelle Probleme schulischer Integration von Kindern mit Lernschwierigkeiten in den Vereinigten Staaten und der Bundesrepublik. Sonderpädagogik, 24(1), 4-13.

Beyene, B., \& Abate, S. T. (2005). Access to information and communication technology (ICT) and education for visual impaired people in Ethiopia. In S. Brüne \& B. Tafla (Eds.), Auf dem Weg zum modernen Äthiopien. Festschrift für Bairu Tafla (pp. 29-47). Münster: LIT-Verl..

Bickenbach, J. E., et al. (1999). Models of disablement, universalism and the international classification of impairments, disabilities and handicaps. Social Science \& Medicine, 48, 1173-1187.

Biewer, G. (2002). Ist die ICIDH-2 für die Heilpädagogik brauchbar? In K. Bundschuh (Ed.), Sonder- und Heilpädagogik in der modernen Leistungsgesellschaft. Krise oder Chance? (pp. 293-301). Bad Heilbrunn/Obb.: Klinkhardt.

Biewer, G. (2009a). Grundlagen der Heilpädagogik und Inklusiven Pädagogik. Bad Heilbrunn: Klinkhardt. 
Biewer, G. (2009b). Vom Verschwinden der Etiketten zum Verlust der Inhalte. Heilpädagogische Klassifizierung im internationalen Vergleich. In A. Bürli, U. Strasser, \& A. D. Stein (Eds.), Integration/Inklusion aus internationaler Sicht (pp. 169-176). Bad Heilbrunn: Klinkhardt.

Birks, M., \& Mills, J. (2011). Grounded theory. A practical guide. Los Angeles/London/New Delhi/Singapore/Washington, DC: Sage.

Booth, T., \& Ainscow, M. (2002). Index for inclusion. Developing learning and participation in schools. London: CSIE Centre for Studies on Inclusive Education.

Braithwaite, J., \& Mont, D. (2008). Disability and poverty: A survey of World Bank poverty assessments and implications. (Discussion Paper No. 0805).

Bulmer, M., \& Warwick, D. P. (1993). Social research in developing countries. Surveys and censuses in the Third world. London: UCL Press.

Burchardt, T. (2004). Capabilities and disability: The capabilities framework and the social model of disability. Disability \& Society, 19(7), 735-751.

Campbell, C. (2010). Disability and international development: Towards inclusive global health. Psychology, Health \& Medicine, 15(5), 622-623.

Chapireau, F. (2005). The environment in the international classification of functioning, disability and health. Journal of Applied Research in Intellectual Disabilities, 18, 305-311.

Cloerkes, G., \& Markowetz, R. (2003). Stigmatisierung und Entstigmatisierung im gemeinsamen Unterricht. Zeitschrift für Heilpädagogik, 54(11), 452-460.

Coleridge, P. (1993). Disability, liberation and development. Oxford: Oxfam.

Denzin, N. K., \& Lincoln, Y. S. (Eds.). (2005). The sage handbook of qualitative research. Thousand Oaks/London/New Delhi: Sage.

Dyson, A. (2007). Sonderpädagogische Theoriebildung im Wandel - ein Beitrag aus Englischer Sicht. In C. Liesen, U. Hoyningen-Süess, \& K. Bernath (Eds.), Inclusive education: Modell für die Schweiz? Internationale und nationale Perspektiven im Gespräch (pp. 93-121). Bern: Haupt.

Elwan, A. (1999). Title, Social Protection Discussion Paper Series. Washington, DC: Social Protection Unit. Human Development Network. The World Bank.

Ethiopian Ministry of Education. (2006). Special needs education program strategy. Emphasising inclusive education to meet the UPEC and EFA goals. Addis Ababa: Ethiopian Ministry of Education.

Ethiopian Ministry of Education. (2012). Education statistics annual abstract. 2004 e.C (2011/2012). Addis Ababa: Ethiopian Ministry of Education, EMIS, Planning and Resource Mobilization Directorate.

Florian, L. (2007). Reimagining special education. In L. Florian (Ed.), The sage handbook of special education (pp. 7-20). London/Thousand Oaks/New Delhi: Sage.

Fujiura, G. T., et al. (2005). Disability statistics in the developing world: A reflection on the meanings in our numbers. Journal of Applied Research in Intellectual Disabilities, 18(4), 295-304.

Grech, S. (2011). Recolonising debates or perpetuated coloniality? Decentring the spaces of disability, development and community in the global South. International Journal of Inclusive Education, 15(1), 87-100.

Hatton, C. (2004). Cultural issues. In E. Emerson et al. (Eds.), The international handbook of applied research in intellectual disabilities (pp. 41-60). Chichester: Wiley.

Hirschberg, M. (2003). Wie wird Behinderung beurteilt? Anmerkungen zum Menschenbild der Klassifikation von Behinderung der Weltgesundheitsorganisation. eWi Report (Vol. 28).

Hollenweger, J. (1998). "Behinderung" neu denken: Ein Schritt nach vorne? Die Revision der Internationalen Klassifikation der Schädigungen, Funktionsstörungen und Beeinträchtigungen (ICIDH). Schweizerische Zeitschrift für Heilpädagogik, 12, 24-29.

Hollenweger, J. (2003). Die Internationale Klassifikation der Funktionsfähigkeit, Behinderung und Gesundheit (ICF) und ihre Bedeutung für Bildungssysteme (Teil II). Schweizerische Zeitschrift für Heilpädagogik, 11, 40-46.

Hollenweger, J. (2006). Der Beitrag der Weltgesundheitsorganisation zur Klärung konzeptueller Grundlagen einer inklusiven Pädagogik. In M. Dederich, H. Greving, \& P. Rödler (Eds.), Inklusion statt Integration? Heilpädagogik als Kulturtechnik (pp. 45-61). Gießen: Psychosozial. 
Holzer, B., et al. (Eds.). (1999). Disability in different cultures: Reflections on local concepts. Bielefeld: Transcript.

Ingstad, B., \& Grut, L. (2005). Using qualitative methods in studying the link between disability and poverty. Developing a methodology and pilot testing in Kenya. Report for SINTEF, Oslo.

Ingstad, B., \& Whyte, S. R. (Eds.). (1995). Disability and culture. Berkeley/Los Angeles/London: University of California Press.

Ingstad, B., \& Whyte, S. R. (Eds.). (2007). Disability in local and global worlds. Berkeley: University of California Press.

Johnson, D. (Ed.). (2008). The changing landscape of education in Africa: Quality, equality and democracy. Oxford: Cambridge University Press.

Kohrman, M. (2005). Bodies of difference. Experiences of disability and institutional advocacy in the making of modern China. Berkeley/Los Angeles/London: University of California Press.

Krishneer, S. (2013). Perspective: For deaf young people, language is the key. In UNICEF (Ed.), The state of the world's children 2013. Children with disabilities (pp. 20-21). New York: UNICEF.

Lawn, M. (Ed.). (2013). The rise of data in education systems. Collection, visualization and use. Oxford: Symposium Books.

Leonhardt, A. (2002). Hörgeschädigtenpädagogik in einem Entwicklungsland - dargestellt am Beispiel der Alpha School for the Deaf in Addis Abeba (Äthiopien). Die neue Sonderschule, 47(5), 333-347.

Luciak, M., \& Khan-Svik, G. (2008). Intercultural education and intercultural learning in Austria Critical reflections on theory and practice. Intercultural Education, 19(5), 493-504.

Mason, M. (2007). Comparing cultures. In M. Bray, B. Adamson, \& M. Mason (Eds.), Comparative education research. Approaches and methods (pp. 165-196). Hong Kong: Springer.

McEwan, C., \& Butler, R. (2007). Disability and development: Different models, different places. Geography Compass, 1(3), 448-466.

Mengistu, L. G. (1994). Psychological classification of students with and without handicaps. A test of Holland's theory in Ethiopia. Jyväskylä: University of Jyväskylä.

Michailakis, D. (2003). The systems theory concept of disability: One is not born a disabled person, one is observed to be one. Disability \& Society, 18(2), 209-229.

Miles, S., \& Ahuja, A. (2007). Learning from difference: Sharing international experiences of developments in inclusive education. In L. Florian (Ed.), The sage handbook of special education (pp. 131-145). London/Thousand Oaks/New Delhi: Sage.

Miles, S., Fefoame, G. O., Mulligan, D., \& Haque, Z. (2012). Education for diversity: The role of networking in resisting disabled people's marginalisation in Bangladesh. Compare: A Journal of Comparative and International Education, 42(2), 283-302.

Minow, M. (1990). Making all the difference: Inclusion exclusion and American law. Ithaca: Cornell University Press.

Mitra, S. (2006). The capability approach and disability. Journal of Disability Policy Studies, 16(4), 236-247.

Mutua, K., \& Swadener, B. (2011). Challenges to inclusive education in Kenya: Postcolonial perspectives and family narratives. In A. Artiles, E. Kozleski, \& F. Waitoller (Eds.), Inclusive education. Examining equity in five continents (pp. 201-222). Cambridge, MA: Harvard Education Press.

Neubert, D., \& Cloerkes, G. (2001). Behinderung und Behinderte in verschiedenen Kulturen. Eine vergleichende Analyse ethnologischer Studien. Heidelberg: Winter "Edition S".

Nieke, W. (2008). Interkulturelle Erziehung und Bildung. Wertorientierungen im Alltag. Wiesbaden: VS Verlag für Sozialwissenschaften.

Norwich, B. (2007). Categories of special educational needs. In L. Florian (Ed.), The sage handbook of special education (pp. 55-66). London/Thousand Oaks/New Delhi: Sage.

Norwich, B. (2008). Dilemmas of difference, inclusion and disability. Routledge: London/New York.

OECD. (2008). Policy brief: Ten steps to equity in education. Retrieved November 23, 2016, from http://www.oecd.org/education/school/39989494.pdf

Oliver, M. (1990). The politics of disablement: A sociological approach. New York: Macmillan.

Peresuh, M., \& Ndawi, O. P. (1998). Education for all - The challenges for a developing country: The Zimbabwe experience. International Journal of Inclusive Education, 2(3), $209-224$. 
Peters, S. (2007a). Inclusion as a strategy for achieving education for all. In L. Florian (Ed.), The sage handbook of special education (pp. 117-130). London/Thousand Oaks/New Delhi: Sage.

Peters, S. (2007b). "Education for all?" A historical analysis of international inclusive education policy and individuals with disabilities. Journal of Disability Policy Studies, 18(2), 98-108.

Samaha, A. M. (2007). What good is the social model of disability? The University of Chicago Law Review, 1251-1308.

Schiemer, M. (2013). Zur Problematik der Interpretation von Daten aus fremden Kulturen. In E. O. Graf (Ed.), Globale Perspektiven auf Behinderung (pp. 129-146). Berlin: epubli GmbH.

Singal, N., \& Muthukrishna, N. (2014). Education, childhood and disability in countries of the South - Re-positioning the debates. Childhood, 21(3), 293-307.

Smart, J. F. (2009). The power of models of disability. Journal of Rehabilitation, 25(2), 3-11.

Srivastava, M., de Boer, A., \& Pijl, S. (2015). Inclusive education in developing countries: A closer look at its implementation in the last 10 years. Educational Review, 2015, 67(2), 179-195.

Stein, R. (2006). Beeinträchtigungen und Behinderungen. In G. Hansen \& R. Stein (Eds.), Kompendium Sonderpädagogik (pp. 9-24). Bad Heilbrunn: Klinkhardt.

Stoltzfus, M., \& Schumm, D. (2011). Editor's introduction. In D. Schumm \& M. Stoltzfus (Eds.), Disability and religious diversity. New York: Palgrave Macmillan.

Tekeste, N. (2006). Education in Ethiopia. From crisis to the brink of collapse. Uppsala: Nordiska Afrikainstitutet.

Terzi, L. (2008). Beyond the dilemma of difference. The capability approach in disability and special educational needs. In L. Florian \& M. J. McLaughlin (Eds.), Disability classification in education. Issues and perspectives (pp. 244-262). Thousand Oaks/London/New Delhi/ Singapore: Corwin Press.

Tirussew, T. (2005). Disability in Ethiopia: Issues, insights and implications. Addis Ababa: Addis Ababa University Printing Press.

Tomlinson, S., \& Abdi, O. A. (2003). Disability in Somaliland. Disability \& Society, 18(7), 911-920.

Turmusani, M. (2004). An eclectic approach to disability research: A majority world perspective. Asia Pacific Disability Rehabilitation Journal, 15(1), 3-11.

UN. (1948). "Allgemeinen Erklärung der Menschenrechte" Resolution 217 a (III) vom 10. 12. 1948. Genf: United Nations.

UN. (2001). Guidelines and recommendations for the development of disability statistics. New York: United Nations.

UN. (2006). Convention on the rights of persons with disabilities and optional protocol. New York: United Nations.

UN. (2015). Sustainable Development Goals (SDG). Retrieved November 23, 2016, from https:// sustainabledevelopment.un.org/topics

UN Enable. (2013). Factsheet on persons with disabilities. Retrieved November 23, 2016, from http://www.un.org/disabilities/documents/toolaction/pwdfs.pdf

UN Secretary General. (2009). Mainstreaming disability in the development agenda, Report for the United Nations Commission for Social Development. New York: United Nations.

UNDP. (2010). The path to achieving the millenium development goals: A synthesis of MDG evidence from around the world. New York: UNDP.

UNESCO. (1960). Convention against discrimination in education. Paris: UNESCO.

UNESCO. (1994). The Salamanca statement and framework for action on special needs education. World conference on special needs education. Access and quality. Paris: UNESCO.

UNESCO. (1996). International commission on education for the twenty-first century. Education: The necessary utopia, Report for UNESCO. Paris: UNESCO.

UNESCO. (2000). The Dakar framework for action. Education for all: Meeting our collective commitments. Paris: UNESCO.

UNESCO (2001). International Bureau of Education. The Development of Education. National Report of Ethiopia by Ethiopian National Agency for UNESCO (Final Version) March 2001. Retrieved on June 6, 2016 from: http://www.ibe.unesco.org/International/ICE/natrap/Ethiopia.pdf

UNESCO. (2003a). Open file on inclusive education. Support materials for managers and administrators. Paris: UNESCO. 
UNESCO. (2003b). Overcoming exclusion through inclusive approaches in education. A challenge and a vision. Paris: UNESCO.

UNESCO. (2005). Guidelines for inclusion: Ensuring access to education for all. Paris: UNESCO.

UNICEF. (2013a). Educating teachers for children with disabilities. Mapping, scoping and best practices exercise in the context of developing inclusive education. Rights, education and protection (REAP) project. (UNICEF) Retrieved November 23, 2016, from https:// dl.dropboxusercontent.com/u/8608264/UNICEF\%20Educating\%20Teachers\%20for\%20 Children\%20with\%20Disabilities1a.pdf

UNICEF. (2013b). The state of the world's children 2013. Children with disabilities, Report for United Nations Children's Fund. New York: UNICEF.

UNESCO. (2001a). International Bureau of Education. The Development of Education. National Report of Ethiopia by Ethiopian National Agency for UNESCO (Final Version) March 2001. Retrieved on June 6, 2016, from http://www.ibe.unesco.org/International/ICE/natrap/Ethiopia. pdf

Üstün, T. B., et al. (Eds.). (2001). Disability and culture. Universalism and culture. ICIDH-2 series. Published on behalf of the world health organisation. Seattle: Hofgrefe \& Huber.

Waldschmidt, A. (2005). Disability Studies: Individuelles, soziales und/oder kulturelles Modell von Behinderung? Psychologie und Gesellschaftskritik, 1, 9-31.

Warnock, H. M. (1978). Special educational needs. Report of the committee of enquiry into the education of handicapped children and young people. Report for English Parliament, Secretary of State for Education and Science, the Secretary of State for Scotland and the Secretary of State for Wales by command of her Majesty, London.

Wedell, K. (2005). Dilemmas in the quest for inclusion. British Journal of Special Education, $32(1), 3-11$.

Wedell, K. (2008). Evolving dilemmas about categorisation. In L. Florian \& M. J. Mc Laughlin (Eds.), Disability classification in education. Issues and perspectives (pp. 47-67). Thousand Oaks/London/New Delhi/Singapore: Sage.

Weisser, J. (2003). "Behinderung": Zur Politik des Begriffs. Eine funktionale Analyse. Schweizerische Zeitschrift für Heilpädagogik, 9(10), 15-22.

Weisser, J. (2005). Behinderung, Ungleichheit und Bildung. Eine Theorie der Behinderung. Bielefeld: Transcript.

WHO. (1980). International classification of impairment, disability and handicap (ICIDH). Geneva: World Health Organization.

WHO. (2001). International classification of functioning, disability and health. Geneva: World Health Organization.

WHO. (2011). World report on disability. Geneva: World Health Organization.

Zehle, J. (2008). Dropout im Schuleingangsbereich an staatlichen Primarschulen Äthiopiens als ein Indikator für Lernschwierigkeiten. Eine wissenschaftliche Untersuchung im Rahmen der interkulturell und international vergleichenden Sonderpädagogik in der qualitativen Eentwicklungszusammenarbeit. Berlin: Logos.

Open Access This chapter is licensed under the terms of the Creative Commons Attribution 4.0 International License (http://creativecommons.org/licenses/by/4.0/), which permits use, sharing, adaptation, distribution and reproduction in any medium or format, as long as you give appropriate credit to the original author(s) and the source, provide a link to the Creative Commons license and indicate if changes were made.

The images or other third party material in this chapter are included in the chapter's Creative Commons license, unless indicated otherwise in a credit line to the material. If material is not included in the chapter's Creative Commons license and your intended use is not permitted by statutory regulation or exceeds the permitted use, you will need to obtain permission directly from the copyright holder.



